Çukurova Üniversitesi Mühendislik Mimarlık Fakültesi Dergisi, 32(4), ss. 71-78, Aralık 2017

Çukurova University Journal of the Faculty of Engineering and Architecture, 32(4), pp. 71-78, December 2017

\title{
Yapı Denetim Firmalarının Sorunlarının Belirlenmesi ve Adana Örneği
}

\author{
Gözde TANTEKIN ÇELIK ${ }^{* 1}$, Cengizhan ÜNAL ${ }^{1}$ \\ ${ }^{1}$ Çukurova Üniversitesi, Mühendislik Mimarlık Fakültesi, İnşaat Mühendisliği Bölümü, Adana
}

Geliş tarihi: 03.06 .2017

Kabul tarihi: 19.12 .2017

$\ddot{\mathbf{O} z}$

Bu çalışmada, yapı denetim firmalarında yaşanan sorunları saptamak ve yapı denetiminde direkt rol alan çalışanların yürürlükteki mevzuat ile ilgili görüşlerini ve çözüm önerilerini belirlemek amacıyla Adana ilinde faaliyet gösteren 73 yapı denetim firması çalışanına bir anket çalışması yapılmıştır. Yapılan çalışma sonucunda, firmaların yapılanmaları ve işleyişi ile ilgili sorunlar tespit edilmiş, yönetimsel ve paydaşlar kaynaklı hatalar belirlenmiş, mevzuat irdelenmiş ve tüm paydaşlara hizmet kalitesini arttırmak için uygulamaya yönelik öneriler sunulmuştur.

Anahtar Kelimeler: İnşaat sektörü, Yapı denetim firmaları, Yapı denetimi hakkında kanun

\section{Determination of Problems in Building Inspection Companies and the Adana Example}

\begin{abstract}
In this study, a survey has been conducted on 73 building inspection company employees who are active in the Adana province in order to determine problems encountered in building inspection companies and the opinions of personel who have a direct role in building inspections on errors in the laws in use, and recommendations for solutions. As a result of the study, the most common errors encountered about problems with the structuring and functioning of firms, administrative and stakeholder related errors have been identified, inspection laws have been assessed, and recommendations towards beter implementation have been suggested to improve the quality of service to all stakeholders.
\end{abstract}

Keywords: Construction industry, Building inspection companies, Law about the construction control

\footnotetext{
*Sorumlu yazar (Corresponding author): Gözde TANTEKIN ÇELIK, gtantekin@cu.edu.tr
} 


\section{GíRiş}

Yaşama, konaklama, ibadet etme, ticaret, spor, sağlık, eğitim, üretim vb. sebeplerle ihtiyaçların karşılanması amacıyla ahşap, taş, tuğla, çelik, betonarme ya da karma malzemelerden; kâgir, karkas ya da prefabrik olarak inşa edilmiş; konut, otel, okul, müze, kütüphane, hastane, dispanser, sağlık ocağı, cami, mescit, sinema, tiyatro, banka, dükkan, iş hanı, atölye, fabrika, terminal, gar, deniz ve hava limanları, stadyum, yüzme havuzu, hipodrom, baraj, su kanalı, köprü, tünel vb. gibi her türlü tesis ve eklere yapı denir.

3194 Sayılı İmar Kanunu'nda yap1; “karada ve suda, daimi veya muvakkat, resmi ve hususi yeraltı ve yerüstü inşaatı ile bunların ilave, değişiklik ve tamirlerini içine alan sabit ve müteharrik tesislerdir." şeklinde tanımlanmaktadır [1].

Yap1 denetimi; can ve mal güvenliğinin temini, imar plânına, fen, sanat ve sağlık kurallarına, standartlara uygun kaliteli yapı yapılması için, işin proje aşamasından iskân izni alınıncaya kadar geçen sürede gerçekleşecek bütün aktiviteleri kapsamaktadır. Yapıların etkin denetlenmesi ile afetlerdeki zararı asgariye çekmek, yapıların güvenilir şekilde inşa edilmesini sağlamak, ülkemizin ve insanımızın sağlıklı ve güvenli bir şehirleşmeye kavuşması hedeflenmektedir. Ancak, yap1 denetim faaliyetlerinin uygulaması aşamasında pek çok sorun ortaya çıkmaktadır.

Ülkemizde 2001 yılında Yapı Denetimi Hakkında Kanun ve ilgili mevzuatın yürürlüğe girmesi [2,3] ile yapı üretiminde kalitenin artması sağlanmıştır. Bununla beraber yapılan çalışmalar halen sistemde sıkıntıların olduğunu göstermektedir [4-11]. Bu çalışmada yapı denetim firmalarının yaşadı $\breve{g}_{1}$ sorunları ve altında yatan sebepleri belirlemek ve çalışanların mevzuata yönelik fikirlerini de saptayarak tüm paydaşlara uygulamaya yönelik önerilerde bulunmak hedeflenmiştir.

\section{2. ÖNCEKİ ÇALIŞMALAR}

$\mathrm{Bu}$ çalışmada; ülkemizde, yapı denetim firmalarının sorunlarını belirlemeye yönelik yapılan çalışmalar incelenmiş [4] ve yapı üretiminde yer alan paydaşlara göre gruplanarak Çizelge 1'de verilmiştir [5-11].

Çizelge 1. Yapı denetimi sırasında karşılaşılan sorunlar

\begin{tabular}{|c|c|c|}
\hline Paydaş & Sorunlar & Kaynak \\
\hline $\begin{array}{l}\text { Proje } \\
\text { Müellifleri }\end{array}$ & $\begin{array}{l}\text { Uygulama } \\
\text { projelerindeki } \\
\text { eksiklikler }\end{array}$ & Açıkel (1998) \\
\hline \multirow[b]{2}{*}{$\begin{array}{l}\text { Şantiye } \\
\text { Şefi }\end{array}$} & İmalatlardaki hatalar & Aç1kel (1998) \\
\hline & $\begin{array}{l}\text { Şantiye şefinin } \\
\text { şantiyede } \\
\text { bulunmaması }\end{array}$ & Doğan (2013) \\
\hline $\begin{array}{l}\text { Şantiye } \\
\text { Şefi/ISSG } \\
\text { Uzmanı } \\
\end{array}$ & $\begin{array}{l}\text { İSG önlemlerinin } \\
\text { yetersiz oluşu }\end{array}$ & Açıkel (1998) \\
\hline Yüklenici & $\begin{array}{l}\text { Yetki belgeli } \\
\text { usta/ustaların tercih } \\
\text { edilmemesi }\end{array}$ & $\begin{array}{l}\text { Karaoğlu } \\
(2011)\end{array}$ \\
\hline \multirow{5}{*}{$\begin{array}{l}\text { Yapı } \\
\text { Denetim } \\
\text { Firmaları }\end{array}$} & $\begin{array}{l}\text { Kontrol elemanlarının } \\
\text { deneyim eksikliği } \\
\text { (Mesleki yetersizlik) }\end{array}$ & $\begin{array}{l}\text { Açıkel (1998), } \\
\text { Sakallı (2008), } \\
\text { Karahan } \\
(2008), \\
\text { Karaoğlu } \\
(2011)\end{array}$ \\
\hline & $\begin{array}{l}\text { Belge yönetiminin } \\
\text { mevzuata uygun } \\
\text { yürütülmemesi }\end{array}$ & Özkan (2005) \\
\hline & $\begin{array}{l}\text { Firma ile yüklenici } \\
\text { firma arasındaki } \\
\text { ilişkiler }\end{array}$ & $\begin{array}{l}\text { Yilmaz (2006), } \\
\text { Karahan } \\
(2008), \text { Doğan } \\
(2013)\end{array}$ \\
\hline & $\begin{array}{l}\text { Firmalar aras1 } \\
\text { rekabetin denetim } \\
\text { bedeline yansimas1 }\end{array}$ & Y1lmaz (2006) \\
\hline & $\begin{array}{l}\text { İstihdam edilen } \\
\text { teknik eleman } \\
\text { sayısının yetersizliği } \\
\end{array}$ & Doğan (2013) \\
\hline $\begin{array}{l}\text { İlgili } \\
\text { İdare }\end{array}$ & Yetersiz denetim & $\begin{array}{l}\text { Açıkel (1998), } \\
\text { Y1lmaz (2006) }\end{array}$ \\
\hline
\end{tabular}

Çizelge 1'de de görüldüğü gibi yapı üretimi sırasında karşılaşılan sorunlar projenin hazırlanması aşamasından başlayarak, projenin uygulama ömrü boyunca devam etmekte ve tüm paydaşları ilgilendiren bir zincir oluşturmaktadır. Yapı üretim süreci; projelerin ve şartnamelerin eksiksiz hazırlanması, yapı üretiminin sözleşme ve eklerine uygun gerçekleştirilmesi, kontrollerin zamanında ve eksiksiz yapılması, belgelerin 
eksiksiz ve mevzuata uygun yönetilmesi gibi pek çok fonksiyonu da içinde barındırmaktadır.

\section{MATERYAL VE METOT}

Yapı denetim firmalarının sorunlarını belirlemek ve yürürlükteki mevzuat ile ilgili görüşlerini almak amacıyla, bu çalışmada Adana ilinde hizmet veren 25 firma ile yüz yüze görüşülerek 73 yapı denetim firması çalışanına anket uygulanmıştır. Uygulanan anket çalışmasından elde edilen verilerin yüzde ve frekans değerleri hesaplanmış, yorumlanmış ve paydaşlara öneriler sunulmuştur.

\section{BULGULAR}

$\mathrm{Bu}$ çalışmaya Adana ilinde faaliyet gösteren 25 yap1 denetim firmasında çalışan 73 çalışan katılmıştır. Örneklemin mesleki dağılımları Çizelge 2'de verilmiştir. Katılımcıların \%59'u inşaat mühendisi, \%18'i makine mühendisi, \%15'i mimar ve \%8'i de elektrik mühendisidir.

Çizelge 2. Katılımcıların mesleki profilleri

\begin{tabular}{|l|c|c|}
\hline Mesleki Profillleri & Frekans (n) & Yüzde (\%) \\
\hline İnşaatMühendisi & 43 & 59 \\
\hline Mimar & 11 & 15 \\
\hline MakineMühendisi & 13 & 18 \\
\hline ElektrikMühendisi & 6 & 8 \\
\hline Toplam & $\mathbf{7 3}$ & $\mathbf{1 0 0}$ \\
\hline
\end{tabular}

Çizelge 3'te katılımcıların yapı denetim firmaları bünyesindeki mesleki deneyim süreleri verilmiştir. Katılımciların \%43,84’ü 0-5 yıl arası, \%31,50'si 6-10 y1l arası ve \%24,66's1 11-15 y1l arası yap1 denetim firmalarında çalışmıştır.

Çizelge 3. Katılımcıların mesleki deneyimi

\begin{tabular}{|l|c|c|}
\hline Mesleki Deneyimleri & Frekans (n) & $\begin{array}{c}\text { Yüzde } \\
(\mathbf{\%})\end{array}$ \\
\hline $0-5$ yıl & 32 & 43,84 \\
\hline $6-10$ yll & 23 & 31,50 \\
\hline $11-15$ yll & 18 & 24,66 \\
\hline Toplam & $\mathbf{7 3}$ & $\mathbf{1 0 0}$ \\
\hline
\end{tabular}

Katılımcılara yapı denetim firmalarının yapılanma ve işleyişleri ile ilgili yetersiz gördükleri konulara yönelik hususlar sorulmuş ve Çizelge 4'teki sonuçlar elde edilmiştir. Çizelge 4 incelendiğinde, personel ücretlerinin azlığ $(\% 49,32)$, teknik personelin kendi branşı ile ilgili bilgi ve deneyim yetersizliği $(\% 30,14)$, meslek disiplini ve etiğinin göz ard1 edilmesi $(\% 23,29)$, projelerin mevcut şartname ve yönetmeliklere göre yeterli düzeyde incelenememesi $(\% 21,92)$, yap1 denetim firmalarının iş yükünün (denetlemekle yükümlü olduğu alan) fazlalığ $1 \% 21,92)$ ve birçok denetçi ve kontrol elemanının sadece diplomalarının ve imzalarının kullanılması $(\% 21,92)$ sorunlarının öne çıktığı görülmüştür. Maaşların zamanında verilememesi ve mevzuat yetersizliği $(\% 1,37)$ cevapları da katılımcıların eklediği cevaplar arasında yer almaktadir.

Çizelge 4. Yapı denetim firmalarının yapılanmaları ve işleyişi ile ilgili sorunlar

\begin{tabular}{|c|c|c|}
\hline \multirow{2}{*}{$\begin{array}{l}\text { Yapı denetim firmalarının } \\
\text { yapılanmaları ve işleyişi ile ilgili } \\
\text { sorunlar }\end{array}$} & \multicolumn{2}{|c|}{ Toplam } \\
\hline & $\mathbf{n}$ & $\%$ \\
\hline Personel ücretlerinin azlı̆̆ 1 & 36 & 49,3 \\
\hline $\begin{array}{l}\text { Teknik personelin kendi branşı ile ilgili } \\
\text { bilgi ve deneyim yetersizliği }\end{array}$ & 22 & 30,1 \\
\hline $\begin{array}{l}\text { Meslek disiplini ve etiğinin gözardı } \\
\text { edilmesi }\end{array}$ & 17 & 23,3 \\
\hline $\begin{array}{l}\text { Projelerin mevcut şartname ve } \\
\text { yönetmeliklere göre yeterli düzeyde } \\
\text { incelenememesi }\end{array}$ & 16 & 21,9 \\
\hline $\begin{array}{l}\text { Yapı denetim firmalarının iş yükünün } \\
\text { (denetlemekle yükümlü olduğu alan) } \\
\text { fazlalığı }\end{array}$ & 16 & 21,9 \\
\hline $\begin{array}{l}\text { Bir çok denetçi ve kontrol elemanının } \\
\text { sadece diplomalarının ve imzalarının } \\
\text { kullanılması }\end{array}$ & 16 & 21,9 \\
\hline $\begin{array}{l}\text { Şirketsahipleriveyöneticilerininuyguladığ } 1 \\
\text { hiyerarşikbaskılar }\end{array}$ & 13 & 17,8 \\
\hline $\begin{array}{l}\text { Denetim için gerekli teknik donanımın } \\
\text { sağlanmaması }\end{array}$ & 11 & 15,1 \\
\hline $\begin{array}{l}\text { İnşaat mahallinde tanzim edilmesi } \\
\text { gereken evrak ve tutanakların masa başı } \\
\text { çalışmalarla düzenlenmesi }\end{array}$ & 11 & 15,1 \\
\hline Teknik personelin sayı olarak yetersizliği & 11 & 15,1 \\
\hline Organizasyon eksikliği & 10 & 13,7 \\
\hline $\begin{array}{l}\text { Denetçi v ekontrol elemanlarının denetim } \\
\text { sürecinde koordine olamaması }\end{array}$ & 7 & 9,59 \\
\hline $\begin{array}{l}\text { İnşaat denetiminin şantiyelerde tam } \\
\text { olarak yapılamaması }\end{array}$ & 7 & 9,59 \\
\hline $\begin{array}{l}\text { Devam eden imalat süreçlerinde sürekli } \\
\text { denetimin yapılmaması }\end{array}$ & 4 & 5,48 \\
\hline $\begin{array}{l}\text { Diğer (Maaşların zamanında } \\
\text { verilmemesi) }\end{array}$ & 1 & 1,37 \\
\hline Diğer (Mevzuat yetersizliği) & 1 & 1,37 \\
\hline
\end{tabular}


Katılımcılara yapı denetimi sırasında yönetim ve paydaşlar ile ilgili karşılaştıkları sorunlar da sorulmuş ve sonuçlar Çizelge 5'te verilmiştir. Katılımcıların karşıllaştıkları sorunlar incelendiğinde sirasıyla; yerel yönetimlerden kaynaklanan sorunlar $(\% 61,64)$, denetlenen taraflar olarak yapı müteahhitlerin işvereni, çalışacakları yap1 denetim firmaların belirleme konusunda yönlendirmeleri ve yapı denetim firmaları ile aralarındaki ticari ilişkiden kaynaklanan sorunlar $(\% 57,53)$, yap1 denetim hizmet bedellerinin yap1 sahibi tarafindan zamanında yatırılmamasından kaynaklanan sorunlar $(\% 52,05)$ ve yapı sahibi veya yüklenicinin proje diș1 imalat isteklerinden kaynaklanan sorunlar $(\% 52,05)$ öne çıkmaktadır.

Çizelge 5. Yapı denetimi sırasında karşılaşılan yönetim ve paydaslar kaynaklı sorunlar

\begin{tabular}{|l|c|c|}
\hline Yapı denetimi sırasında karşılaşılan & Toplam \\
\cline { 2 - 4 } sorunlar & $\mathbf{n}$ & $\%$ \\
\hline Yerel yönetimlerden kaynaklanan sorunlar & 45 & 61,64 \\
\hline $\begin{array}{l}\text { Denetlenen taraflar olarak yapı sahibi veya } \\
\text { yapı müteahhitlerinin, çalışacakları yapı } \\
\text { denetim firmalarını belirlemeleri ve } \\
\text { aralarındaki ticari ilişkiden kaynaklanan } \\
\text { sorunlar }\end{array}$ & 42 & 57,53 \\
\hline $\begin{array}{l}\text { Yapı denetim hizmet bedellerinin yapı sahibi } \\
\text { tarafından zamanında yatırılmamasından } \\
\text { kaynaklanan sorunlar }\end{array}$ & 38 & 52,05 \\
\hline $\begin{array}{l}\text { Yapı sahibi veya yüklenicinin proje dışı imalat } \\
\text { isteklerinden kaynaklanan sorunlar }\end{array}$ & 38 & 52,05 \\
\hline $\begin{array}{l}\text { 4708 sayılı Yapı Denetim Kanunu'ndan } \\
\text { kaynaklanan sorunlar }\end{array}$ & 30 & 41,1 \\
\hline $\begin{array}{l}\text { Yapı üretim sürecinde görev alan usta, kalfa } \\
\text { ve işçi gibi meslek mensuplarının eğitimsiz ve } \\
\text { vasıfsız olmasından kaynaklanan sorunlar }\end{array}$ & 25 & 34,25 \\
\hline $\begin{array}{l}\text { Yapı Denetim Yönetmeliği’nden kaynaklanan } \\
\text { sorunlar }\end{array}$ & 23 & 31,51 \\
\hline İmar planlarından kaynaklanan sorunlar & 22 & 30,14 \\
\hline $\begin{array}{l}\text { Kanunla belirlenmiş denetim ücretinin yapı } \\
\text { maliyetine oranla düşük tutulmasından } \\
\text { kaynaklanan sorunlar }\end{array}$ & 21 & 28,77 \\
\hline $\begin{array}{l}\text { Proje dışı imalatlarla ilgili caydırııı } \\
\text { yaptırımların olmayışından kaynaklanan } \\
\text { sorunlar }\end{array}$ & 21 & 28,77 \\
\hline Uygulama projeleri arasındaki uyumsuzluklar & 20 & 27,4 \\
\hline $\begin{array}{l}\text { Çevreve Şehircilik Bakanlığı’ndan } \\
\text { kaynaklanan sorunlar }\end{array}$ & 12 & 16,44 \\
\hline $\begin{array}{l}\text { Denetim mühendis ve mimarlarının sayı } \\
\text { olarak yetersizliğinden kaynaklanan sorunlar }\end{array}$ & 4 & 5,48 \\
\hline $\begin{array}{l}\text { Yapı malzemelerini ilgili standartlara gore } \\
\text { ölçen laboratuarlardan kaynaklanan sorunlar }\end{array}$ & 3 & 4,11 \\
\hline
\end{tabular}

Katılımcılara yapı denetim uygulamalarında yaşanan sorunlara yönelik çözüm önerileri sorulmuş ve öneriler Çizelge 6'da verilmiştir.

Çizelge 6. Yap1 denetim uygulamalarında yaşanan sorunlar için çözüm önerileri

\begin{tabular}{l|l} 
Toplam \\
\cline { 2 - 2 }
\end{tabular}

Yapı denetim kuruluşlarına gereğinden fazla

bürokratik işlemler yüklenmesi yerine, şantiye

denetimlerine yönelik görev tanımlarının daha detaylı yapılması

Müteahhitlik yapacak kişilerin mesleki

yeterliliğinin ve yetkinliğinin belirlenmesi ve mesleki denetim mekanizmasının kurulması

Yapı denetim șirketlerinde çalıșan

mühendislerin özlük haklarının ve ücretlerinin

belli bir standard bağlanarak güvence altına

alınması

Denetimi yapılacak yapılar için yapı denetim sirketlerinin, merkezi bir havuz sistemi

vasitasiyla belirlenmesi

İnşaat usta ve kalfalarının sorumluluklarının

belirlenmesi ve gerekli durumlarda cezai

yaptırımlar uygulanması

4708 YDK'nın 8. Madde'sinde belirtilen parasal

cezalara ișin yüklenicisinin de eklenmesi

Yapı denetim şirketlerine cezai yaptırımlarla

ilgili yetkiler verilmesi

Fesih olan veya kapatılan yapı denetim

firmalarında yarım kalan işler genelde yeni yap

denetim firmaları tarafindan üstlenilmek

istenmemektedir. Bu bakımdan, yarım kalan

yapılarda denetimin yeni yapı denetim

firmasinca üstlenilmesinin devlet tarafindan

cazip hale getirilmesinin sağlanması (Devlet

tarafindan parasal katkı veya devlet tarafindan

yapı denetim hizmeti verilmesi)

Yapı denetiminde meslek odalarının sürece daha etkin katılımının sağlanması

Yapım işleri yürütülen şantiyede, mühendis veya

mimar diplomasına sahip bir șantiye șefinin

bulundurulması maddesine, tekniker, teknik

ögretmen ve teknisyenlerin eklenmesi

5237 TCK.'nunda imar kirliliğinin ortadan

kalkması (Ruhsata aykırı olarak yapılan

binaların imar planına ve ruhsatına uygun hale

getirilmesi) ile her türlü ceza hükümleri

kalkmasına rağmen, 4708 sayılı YDK'nuna gore

idari cezalar imar kirliliğ̣i ortadan kalkmasına

rağmen uygulanmaktadır. Bu çelişkinin

giderilmesinin sağlanması

Yapı denetim izin belgesiverilmesi sürecinde

bakanlıkça belirlenecek miktarda nakit para,

banka teminatı veya hazine bonosunun teminat

olarak alınması

Diğer (Santiye șefleri sadece inșaat mühendisi olmalı)

\begin{tabular}{|c|c|}
\hline 16 & 21,92 \\
\hline 6 & 8,22 \\
\hline 4 & 5,48 \\
\hline
\end{tabular}


Katılımcıların çözüm önerileri incelendiğinde sırasıyla; yapı denetim kuruluşlarına gereğinden fazla bürokratik işlemler yüklenmesi yerine, şantiye denetimlerine yönelik görev tanımlarının daha detaylı yapılması $(\% 58,90)$, müteahhitlik yapacak kişilerin mesleki yeterliliğinin ve yetkinliğinin belirlenmesi ve mesleki denetim mekanizmasının kurulması $(\% 56,16)$, yapı denetim şirketlerinde çalışan mühendislerin özlük haklarının ve ücretlerinin belli bir standarda bağlanarak güvence altına alınması $(\% 53,42)$ ve denetimi yapılacak yapılar için yapı denetim şirketlerinin, merkezi bir havuz sistemi vasıtasıyla belirlenmesi $(\% 49,32)$ en çok önerilen konulardır. Bunlara ek olarak şantiye şeflerinin sadece inşaat mühendisi olması da $(\% 5,48)$ katılımcılar tarafından önerilmiştir.

Katılımcılara 2001 yılında yürürlüğe giren Yapı Denetimi Hakkında Kanun ve ilgili mevzuatın yapı denetimine olumlu katkısı olup olmadığı sorulmuş ve sonuçlar Çizelge 7'de verilmiştir. Çizelge 7. incelendiğinde katılımcıların \%87,68'i 4708 Sayılı kanunun yapı denetimini olumlu yönde etkidiğini yönünde görüş bildirdikleri görülmüştür.

Çizelge 7. Katılımcıların yapı denetimi hakkında kanunun yap1 denetimine katkıs1 hakkındaki görüşleri

\begin{tabular}{|l|c|c|}
\hline \multirow{2}{*}{ Cevaplar } & \multicolumn{2}{|c|}{ Toplam } \\
\cline { 2 - 3 } & n & \% \\
\hline Kesinlikle katıliyorum & 29 & 39,73 \\
\hline Katıliyorum & 35 & 47,94 \\
\hline Fikrim yok & 5 & 6,85 \\
\hline Katılmiyorum & 4 & 5,48 \\
\hline Kesinlikle katılmiyorum & 0 & 0,00 \\
\hline Toplam & 73 & 100 \\
\hline
\end{tabular}

Katılımcılara 4708 Sayılı Yapı Denetimi Hakkında Kanun ve ilgili mevzuatı yeterli bulup bulmadıkları sorulmuş ve sonuçlar Çizelge 8 'de verilmiştir. Çizelge 8 incelendiğinde, katılımcıların \%56'sının Yap1 Denetimi Hakkında Kanun'u yeterli bulmadıkları, \%40'ının ise yeterli bulduğu görülmektedir.
Çizelge 8. Katılımcıların yapı denetimi hakkında kanun ile ilgili görüşleri

\begin{tabular}{|l|c|c|}
\hline \multirow{2}{*}{ Cevaplar } & \multicolumn{2}{|c|}{ Toplam } \\
\cline { 2 - 3 } & $\mathbf{n}$ & $\mathbf{\%}$ \\
\hline Kesinlikle katıliyorum & 5 & 7 \\
\hline Katıliyorum & 24 & 33 \\
\hline Fikrim yok & 3 & 4 \\
\hline Katılmıyorum & 28 & 38 \\
\hline Kesinlikle katılmiyorum & 13 & 18 \\
\hline Toplam & 73 & 100 \\
\hline
\end{tabular}

Katılımc1lara 4708 sayılı Yapı Denetim Hakkında Kanun ve yönetmeliğiyle ilgili yeniden düzenlenmesi gereken konular ile ilgili görüşleri sorulmuş ve sonuçlar Çizelge 9'da verilmiştir.

Çizelge 9. Yapı denetimi hakkında kanun ve ilgili mevzuatta yapılabilecek değişikliklere yönelik öneriler

\begin{tabular}{|c|c|c|}
\hline \multirow{2}{*}{$\begin{array}{l}\text { Yapı Denetimi Hakkında Kanun ve ilgili } \\
\text { mevzuata yönelik yapılabilecek } \\
\text { değişikliklere yönelik öneriler }\end{array}$} & \multicolumn{2}{|c|}{ Toplam } \\
\hline & $\mathbf{n}$ & $\%$ \\
\hline $\begin{array}{l}4708 \text { Sayılı Kanunun 5. Madde'si ile yapı } \\
\text { denetimi hizmet sözleşmelerinin yapı sahibi } \\
\text { ile yapı denetim kuruluşu arasında } \\
\text { akdedilmesi, bir bakıma istenilen yapı } \\
\text { denetim firmasının seçilebilmesi }\end{array}$ & 37 & 50,68 \\
\hline $\begin{array}{l}\text { Yasa ile yapı denetim kuruluşlarına denetim } \\
\text { yetki ve sorumluluğu verilmiş olmasına } \\
\text { karşın ruhsat ve eklerine aykırı uygulama } \\
\text { yapılması halinde durumu ilgili idareye } \\
\text { bildirmek dışında bir yaptırımının } \\
\text { bulunmaması }\end{array}$ & 35 & 47,95 \\
\hline Yapı denetim şirketleri sayısının fazla olması & 33 & 45,21 \\
\hline $\begin{array}{l}3194 \text { Sayılı Kanunun } 26 . \text { Madde'sinde } \\
\text { belirtilen kamuya ait yapı ve tesislerin } \\
\text { kapsam dışında tutulması }\end{array}$ & 32 & 43,84 \\
\hline $\begin{array}{l}\text { Yapının ruhsat ve eklerine, fen, sanat ve } \\
\text { sağlık kurallarına aykırı, eksik, hatalı ve } \\
\text { kusurlu yapılmış olması nedeniyle ortaya } \\
\text { çıkan yapı hasarından dolayı sorumluluğun } \\
\text { taşıyıı olmayan kısımlarda iki yıl olarak } \\
\text { belirlenmiş̧ olması }\end{array}$ & 8 & 10,96 \\
\hline $\begin{array}{l}\text { Yapılan hatalı imalatı ve eleman } \\
\text { değişikliklerinin } 3 \text { iş günü içerisinde ilgili } \\
\text { idarelere bildirilmesi }\end{array}$ & 8 & 24,66 \\
\hline $\begin{array}{l}\text { Köy yerleşik alanlarında ve nüfusu } 5000 \text { 'in } \\
\text { altında olan belediyelerde toplam inşaat alanı } \\
500 \text { metrekareyi geçmeyen yapıları yasa } \\
\text { kapsamı dışında tutulmuş olması }\end{array}$ & 6 & 21,92 \\
\hline $\begin{array}{l}\text { Yap1 denetim şirketlerinin ve denetçi mimar, } \\
\text { mühendislerin denetlemekle yetkili kılındığ } \\
\text { yapı metrekarelerinin fazlalı̆ğ }\end{array}$ & 5 & 20,55 \\
\hline
\end{tabular}


Katılımcıların yapı denetim mevzuatı ile ilgili değişiklik yapılması gereken konulara ait önerileri incelendiğinde sirasıyla; 4708 Sayılı Kanunun 5. Maddesi ile yap1 denetimi hizmet sözleşmelerinin yap1 sahibi ile yap1 denetim kuruluşu arasında akdedilmesi, bir bakıma istenilen yapı denetim firmasının seçilebilmesi $(\% 50,68)$, yasa ile yapı denetim kuruluşlarına denetim yetki ve sorumluluğu verilmiş olmasına karşın ruhsat ve eklerine aykırı uygulama yapılması halinde durumu ilgili idareye bildirmek dişında bir yaptırımının bulunmaması $(\% 47,95)$, yap1 denetim şirketleri sayısının fazla olması $(\% 45,21), 3194$ Sayılı Kanunun 26. Maddesi'nde belirtilen kamuya ait yap1 ve tesislerin kapsam dişında tutulması $(\% 43,84)$ konularının öne çıktığı görülmektedir.

\section{SONUÇ VE ÖNERILLER}

Yapı denetimi pek çok paydaşın dahil olduğu bir faaliyetler topluluğudur. Paydaşların tümünün üstüne düşen görevi eksiksiz yapması hem yapıların olabildiğince sorunsuz üretilebilmesini sağlayacak hem de yapı denetimi yapan çalışanların iş yükünü azaltacaktır. Yapı üretimindeki tüm paydaşları ilgilendiren öneriler aşağıda sıralanmıştır.

- Şantiye şeflerinin düzenli olarak şantiyede bulunmalar1,

- Proje müelliflerinin uygulama projelerini sözleşme ve eklerine uygun ve eksiksiz, çelişkiye yer vermeyecek titizlikte hazırlamaya gayret etmeleri,

- Sözleşme ve eklerinin titizlikle hazırlanması, keşif artışı gibi durumlarda uygulanacak prosedürün önceden sözleşmede detaylı olarak açıklanması,

- Yapı denetim çalıșanlarının ücretlerinin arttırılması ve deneyimli personel tercih edilmesi,

- Yapı denetim çalışanlarının bir bölümünün sadece diploma ve imzalarının kullanılmaması, fiili olarak çalışmaları gerekliliği,

- Yapı denetim çalışanlarının düzenli olarak şantiyeye gitmeleri gerekliliği,

- Yapı denetim firmalarının iş yükü fazlalığının azaltılması,
- Yapı denetim firmalarının uygulayabileceği yaptırımların arttırılması,

- Yap1 denetim firmalar1 tarafindan düzenlenmesi/kontrol edilmesi gereken evrak yükünün azaltılması,

- Müteahhit firmanın yapı denetim firmas1 seçimini etkileme ihtimalini önlemek amacıyla yapı denetim firmaları için havuz sistemi uygulamas1,

- Eğitimli taşeron ekip tercih edilmesi,

- Müteahhitlik yapacak kişilerin belli bir eğitim seviyesinde olması ya da eğitim görmesi gerekliliği,

- Yapı sahibinin ödemeleri düzenli yapması,

- Tüm paydaşların meslek etiğine uygun hareket etmeleri önerilmektedir.

\section{KAYNAKLAR}

1. İmar Kanunu, Web Sitesi http://mevzuat.basbakanlik.gov.tr/ $\quad$ Erişim Tarihi: 19.12.2016.

2. Yapı Denetimi Hakkında Kanun, Web Sitesi, http://www.mevzuat.gov.tr/MevzuatMetin/1.5. 4708.pdf, Erişim Tarihi: 19.12.2016.

3. Yapı Denetimi Uygulama Yönetmeliği, Web Sitesi, http://www.csb.gov.trErișim Tarihi: 19.12.2016.

4. Ünal, C., 2017. Yapı Denetim Firmalarının Sorunlarının Belirlenmesi ve Adana Örneği, Yüksek Lisans Tezi, Çukurova Üniversitesi, Fen Bilimleri Enstitüsü, Adana.

5. Açıkel, A., 1998. Yap1 Denetimin Kalite Üzerine Etkisi ve Konya Örneği, Yüksek Lisans Tezi, Selçuk Üniversitesi, Fen Bilimleri Enstitüsü, Konya.

6. Doğan, A., 2013. Ankara'da Yap1 Denetim Sorunlarının Belirlenmesiyle İlgili Bir Saha Çalışması, Yüksek Lisans Tezi, Gazi Üniversitesi, Fen Bilimleri Enstitüsü, Ankara.

7. Karaoğlu, E., 2011. 4708 Sayılı Yapı Denetim Kanununun Denetimdeki Verimliliği, Yüksek Lisans Tezi, Yıldız Teknik Üniversitesi, Fen Bilimleri Enstitüsü, İstanbul.

8. Sakallı, F., 2008. Yap1 Denetim Sisteminde Yaşanan Sorunlar, 4708 Sayılı Yapı Denetim Hakkında Kanun'daki Eksiklikler ve Çözüm Önerileri, Yüksek Lisans Tezi, İstanbul 
Teknik Üniversitesi, Fen Bilimleri Enstitüsü, İstanbul.

9. Karahan, A.Y., 2008. İstanbul'da Faaliyet Gösteren Yap1 Denetim Şirketlerinin Uygulamaya Yönelik Karşılaştıkları Sorunlar ve Çözüm Önerilerine Yönelik bir Araştırma, Yüksek Lisans Tezi, Yıldız Teknik Üniversitesi, Fen Bilimleri Enstitüsü, İstanbul.

10. Özkan, G., 2005. Türkiye'de Yap1 Denetim Sistemi İle İlgili Yaklaşımlar, Yüksek Lisans Tezi, Yıldız Teknik Üniversitesi, Fen Bilimleri Enstitüsü, İstanbul.

11. Yılmaz, H., 2006. Türkiye'de 1980'den Sonra Kent Planlaması Hizmetlerinin Özel Kesime Gördürülmesi Eğilimleri: Yap1 Denetim Kuruluşları Örneği, Doktora Tezi, Ankara Üniversitesi, Sosyal Bilimler Enstitüsü, Ankara. 
